\title{
CONTRIBUIÇÕES DA GEOGRAFIA PARA EDUCAÇÃO ESCOLAR INDÍGENA: POSSIBILIDADES POR MEIO DAS PRÁTICAS DESENVOLVIDAS POR PROFESSORES ATUANTES NAS ESCOLAS INDÍGENAS DOS MUNICÍPIOS DE AMAMBAI (MS), CAARAPÓ (MS) E DOURADOS (MS)
}

\author{
Geography contributions for indigenous school education: possibilities through the practices \\ developed by acting teachers in the indigenous schools of Amambai (MS), Caarapó (MS) and \\ Dourados (MS)
}

\begin{abstract}
Resumo:
Neste texto apresentamos parte das reflexões desenvolvidas em nossa pesquisa de doutorado. A pesquisa tem por objetivo central analisar as práticas dos professores de Geografia atuantes nas escolas indígenas dos municípios de Dourados (MS), Caarapó (MS) e Amambaí (MS) na tentativa de apontar possibilidades para a efetivação da educação intercultural. A reflexão realizada até o momento possibilitou identificarmos práticas e/ou ações de professores que produzem possibilidades de trabalhar Geografia visando ao diálogo com os elementos da vivência e da realidade dos alunos indígenas, aproximando-se do que acreditamos ser um caminho para a construção de uma educação intercultural.
\end{abstract}

Palavras-chave: Geografia; Escolas indígenas, Educação intercultural.

\begin{abstract}
:
In this paper we present part of the reflections developed in our doctoral research. Its aim is to analyze the practices of Geography teachers who work in the indigenous reserve schools of Dourados (MS), Caarapó (MS) and Amambaí (MS) in an attempt to point out possibilities for intercultural education. The reflections made so far allowed us to identify some teachers' practices and/or actions that produce possibilities of working Geography aiming at the dialogue with the indigenous students' reality and experience elements, approaching what we believe to be a way for the construction of an intercultural education.
\end{abstract}

Keywords: Geography; Indigenous schools, Intercultural education.

\section{Introdução}

Esta pesquisa desdobra-se da dissertação de mestrado intitulada "A Geografia na educação escolar indígena: limites e possibilidades para a construção da educação intercultural", na qual identificamos professores de Geografia que, ao vivenciarem as dificuldades educacionais e sociais da Reserva Indígena de Dourados, buscam construir no cotidiano da sala de aula novas possibilidades, ou seja, tendo como referência um currículo formal com conteúdos estabelecidos, propõem diálogo com as 
realidades vividas pelos alunos, no interior ou fora da Reserva, criando, assim, linhas de fuga ao modelo hegemônico vigente. (SILVA, 2013)

Para a pesquisa em nível de Doutorado em desenvolvimento ampliamos nosso recorte de análise para as escolas indígenas dos municípios de Dourados (MS) Amambai (MS) e Caarapó (MS) e buscamos identificar nas práticas dos professores de Geografia atuantes nas escolas indígenas dos referidos municípios possibilidades outras ao pensamento geográfico, rasuras ao ensino formal instituído, enquanto potencialidade para a educação intercultural.

Para atingirmos esse objetivo estamos realizando os seguintes procedimentos metodológicos: revisão bibliográfica sobre o tema; análise dos principais referenciais curriculares sobre educação escolar indígena no Brasil; identificação e mapeamento das escolas indígenas dos municípios abrangidos pela pesquisa; levantamento e análise dos projetos pedagógicos das escolas; realização de entrevistas semi-estruturadas com coordenadores pedagógicos e professores de Geografia das escolas indígenas e acompanhamento in loco das aulas de Geografia nas escolas indígenas dos municípios pesquisados.

De maneira geral, as entrevistas realizadas com os coordenadores e professores atuantes nas escolas indígenas dos três municípios pesquisados, demonstram o reconhecimento e respeito para com a diversidade cultural. Propõe-se o diálogo entre os saberes indígenas e os conhecimentos não indígenas, mas numa perspectiva que se aproxima da interculturalidade funcional a qual busca promover o diálogo sem questionar as relações de poder existente no (des)encontro entre os diferentes grupos socioculturais existentes.

Essa situação/condição evidencia os limites existentes na Geografia trabalhada nas escolas indígenas, o que aponta para a necessidade de buscarmos novas possibilidades para o ensino de Geografia nessas escolas. Entendemos que é preciso buscar propostas pedagógicas para a afirmação da diferença, da luta contra as manifestações de discriminação. Uma educação capaz de compreender a identidade e a diferença em suas especificidades, rompendo assim, com a ideia simplista de tolerância e respeito para com a diversidade.

Entendemos que os confrontos contra as relações de poder existentes, são elementos centrais nas aulas de Geografia, em especial, no contexto de escolas indígenas, uma vez que, esta disciplina é uma importante ferramenta capaz de levar os alunos a compreenderem o sentido de estarem em um lugar e, portanto, a ele pertencerem, e assim, criarem estratégias de sobrevivência.

No que se refere às práticas dos professores de Geografia nas escolas indígenas dos municípios pesquisados, identificamos alguns professores que procuram a partir da realidade em que se encontram, possibilitar aos alunos um novo olhar ao mundo, construindo coletivamente, operando ações de transformações por mínimas que sejam. Na sequência, destacaremos alguns desses trabalhos no intuito de identificarmos e analisarmos as diferentes geografias existentes nos contextos das escolas indígenas pesquisadas.

\section{As práticas docentes e suas aproximações com a perspectiva intercultural}

Para analisarmos a prática dos professores de Geografia das escolas indígenas dos três municípios abrangidos por esta pesquisa, nos pautaremos na ideia de Castellar; Moraes; Sacramento (2014, p. 256), para as quais "Pensar o ensino de Geografia, é analisar quais conceitos, habilidades e atitudes são pertinentes para a aprendizagem significativa do aluno".

Ao possibilitar aos alunos uma contextualização espacial dos fenômenos em suas diferentes escalas (local, regional, nacional, mundial), o professor contribui para melhor compreensão de que suas práticas sociais cotidianas são práticas espaciais. "Se ajudarmos nossos alunos a perceberem que a Geografia trabalha com as materializações das práticas sociais, estaremos colocando-a no seu cotidiano". (KAERCHER, 2002, p.6) 
Para Santos (2016, p.28):

[...] estudar Geografia é um direito, pois, por tradição, ela nos expõe às reflexões sobre "o onde das coisas do mundo" e, assim, identificando a localização dos objetos e dos processos que a eles estão associados, podemos aprimorar nossa capacidade de reconhecermos o onde de nós mesmos e dos outros. (Grifos do autor)

Segundo Santos (2016, p. 24) "Saber onde se está é condição básica de sobrevivência, e construir referências simbólicas associadas a tal necessidade foi o fundamento que deu sentido ao que hoje chamamos de cultura". Acreditmos que a ideia de Santos (2016) dialoga com o pensamento do professor Kaiowa César Benites que destacou, em entrevista pessoal a nós concedida, que a Geografia é o carro chefe da educação escolar indígena, uma vez que ela está relacionada à localização, a forma de olhar a terra como ferramenta de sobrevivência.

Por exemplo, os rios, a vegetação, o clima, o relevo. Tudo isso era importante para os Guarani e Kaiowá ocuparem seu território, próximos aos rios, com solos férteis para plantar, vegetação e clima propícios para sobreviver, a caça, a questão dos rios, a pesca, água. A Geografia é importantíssima para o indígena, porque a partir daí ele vai conhecer a sua localização. Entender o porquê hoje nós estamos vivendo em um lugar (Reserva), onde não existe rio, em um espaço reduzido, área de 3.539 hectares para aproximadamente 15.000 pessoas. A localização da Reserva não foi escolhida pelos indígenas. Não considerou o modo de viver Guarani Kaiowá. (Professor Cesar Benites, em entrevista pessoal no dia $24 / 11 / 2015)$

A análise do professor César Benites caminha no sentido apontado por Santos (2007, p.2) de que a Geografia corresponde a "certo tipo de comportamento associado diretamente às nossas necessidades de sobrevivência". Para o referido autor:

Na construção do discurso geográfico, isto é, na medida em que sabemos que os assuntos tratados pela Geografia também podem ser tratados por todos os demais campos de conhecimento é preciso que saibamos qual seria, de fato, a identidade do discurso geográfico e ela, com certeza, não está nos assuntos que podemos tratar com nossos alunos. 0 que importa é que devemos tomar todo o cuidado para, ao falar sobre as coisas do mundo, o façamos como geógrafos, isto é, tendo como referência a localização das coisas e processos que fazem parte do fenômeno sobre o qual falamos e, finalmente, que tenhamos a condição de refletir o significado que tais localizações possuem na definição das características que queremos realçar em cada assunto que estejamos a tratar. (SANTOS, 2007, p.6)

A reflexão de Santos (2007) se aproxima da prática desenvolvida pela professora de Geografia Escola Municipal Indígena Araporã Alice Rosane Benites que desenvolve uma série de atividades nas quais fica evidenciado que a mesma possibilita aos alunos questionamentos quanto aos significados de estarem em áreas de acomodação ${ }^{1}$ (localização) e as consequências desse processo para a vida da comunidade.

Como podemos verificar na figura 1, os alunos demonstram a rotina do modo de vida Guarani e Kaiowá antes da chegada dos colonizadores/invasores, por meio do padrão de organização tradicional, com moradias próximas a recursos naturais necessários para sua sobrevivência (a caça, a pesca, as

\footnotetext{
1 A opção pelo conceito de área de acomodação se deu com base na reflexão de Levi Marques Pereira que acredita que ele permite expressar aspectos importantes da dimensão espacial, econômica, política e principalmente cultural das figurações sociais kaiowá desenvolvidas nas Reservas. Isto porque, na situação de reserva, os Kaiowá passam a mobilizar todos os referenciais disponíveis no sentido de gerar formas organizacionais capazes de tornar viável a sobrevivência física e a construção de figurações sociais que, de alguma maneira, assegurem a continuidade de sua formação social. (PEREIRA, 2007, p.7)
} 
matas, rios), a vida comunitária evidenciada por meio da disposição das residências e/ou do pertencimento ao fogo doméstico ${ }^{2}$, "pré-condição para a existência humana na sociedade kaiowá" (PEREIRA, 2002, p. 14)

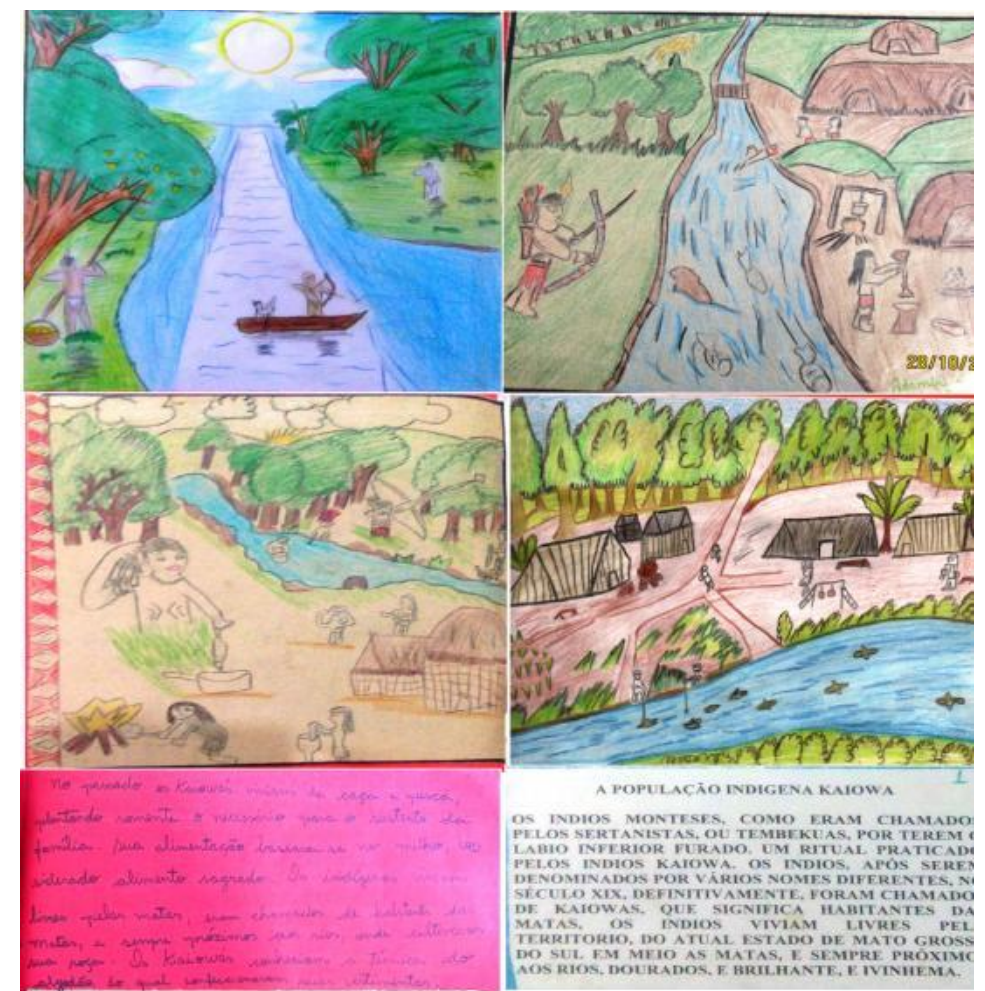

Figura 1: Modo de vida tradicional - Guarani/Kaiowá

Autoria: Trabalhos elaborados pelos alunos da Escola Araporã sob orientação da professora Alice.

Fonte: Trabalho de campo, 2015

Chama atenção nos desenhos a "ausência" de limites territoriais evidenciados pela ideia de liberdade contida no horizonte dos desenhos 1 e 2 da Figura 1 ou nos caminhos existentes no interior da imagem 4 da mesma figura que conduzem a lugares primordiais para o modo de ser e viver Guarani e Kaiowá: caminho da mata, caminhos do rio, caminho para casa de reza, etc.

Mas a liberdade até aquele momento vivenciada foi interrompida pela chegada inesperada do "outro", evidenciada no desenho da Figura 2 em que os alunos ilustraram os primeiros contatos entre os povos indígenas e os "colonizadores", marcados pelo "desencontro de temporalidades históricas, pois cada um desses grupos está situado diversamente no tempo da História". (MARTINS, 1997, p.27)

\footnotetext{
20 fogo constitui a unidade sociológica mínima no interior do grupo familiar extenso ou parentela, composta por vários fogos, interligados por relações de consangüinidade, afinidade ou aliança política. (PEREIRA, 2004, p. 7)
} 


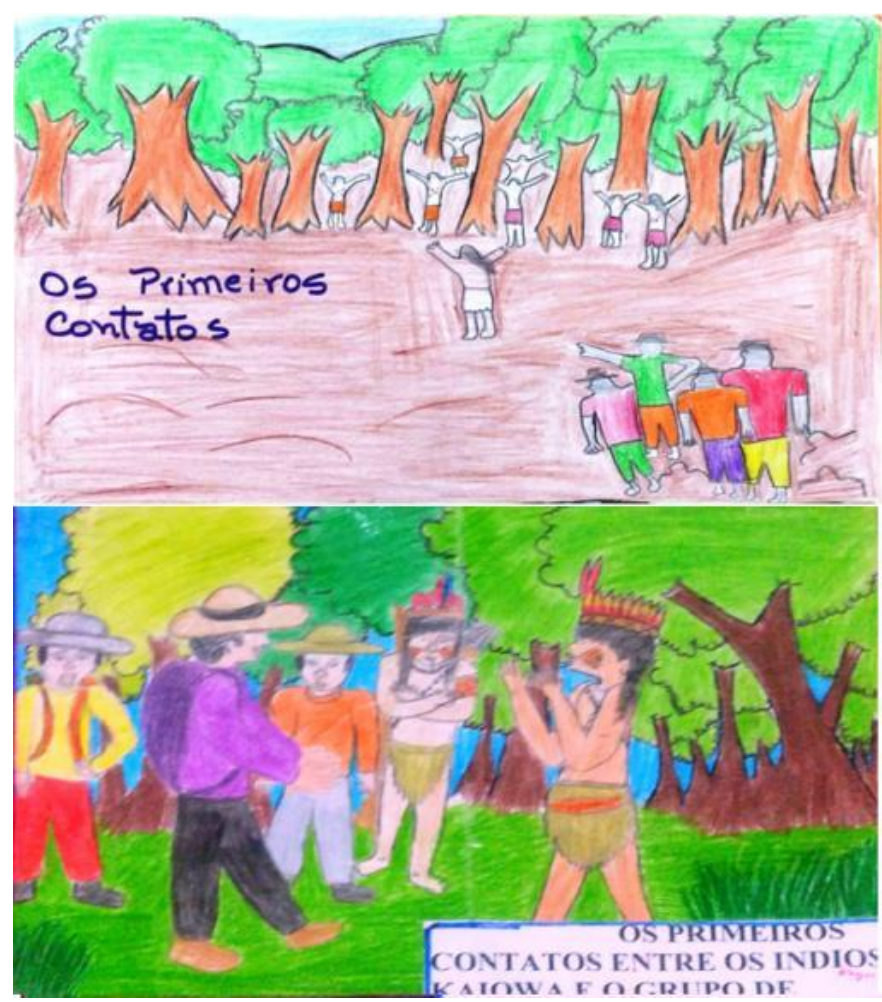

Figura 2: Primeiros contatos dos Kaiowá com os Karaí

Autoria: Trabalhos elaborados pelos alunos da Escola Araporã, sob orientação da professora Alice.

Fonte: Trabalho de campo, 2015

No canto inferior do desenho 1 da Figura 2, o colonizador/invasor estica o braço em um movimento que, no primeiro olhar, nos remete a imagem do líder no ato de ordem à invasão e dominação do território. Na parte superior do mesmo desenho, os indígenas, com um gesto de sociabilidade, ao estenderem a mão, confundem-se com as árvores, demonstrando pertencimento ao território e, consequentemente, a diferentes lógicas e visões de mundo. 0 encontro de duas espacialidades irreconhecíveis, irreconciliáveis, radicalmente outras, outros espaços, outros sujeitos. (SKLIAR, 2003)

Todavia, no desenho 2 da Figura 2 os alunos ilustram a tentativa de diálogo, de troca entre esses diferentes saberes e lógicas. As ilustrações dos alunos corroboram com a análise de Freire (2009, p. 13) para o qual a interculturalidade é "resultado da relação entre culturas, da troca que se dá entre elas". Mas no caso específico dos povos indígenas, o problema é que essa troca, em grande parte, fora imposta a "ferro e a fogo". (Figura 3) 

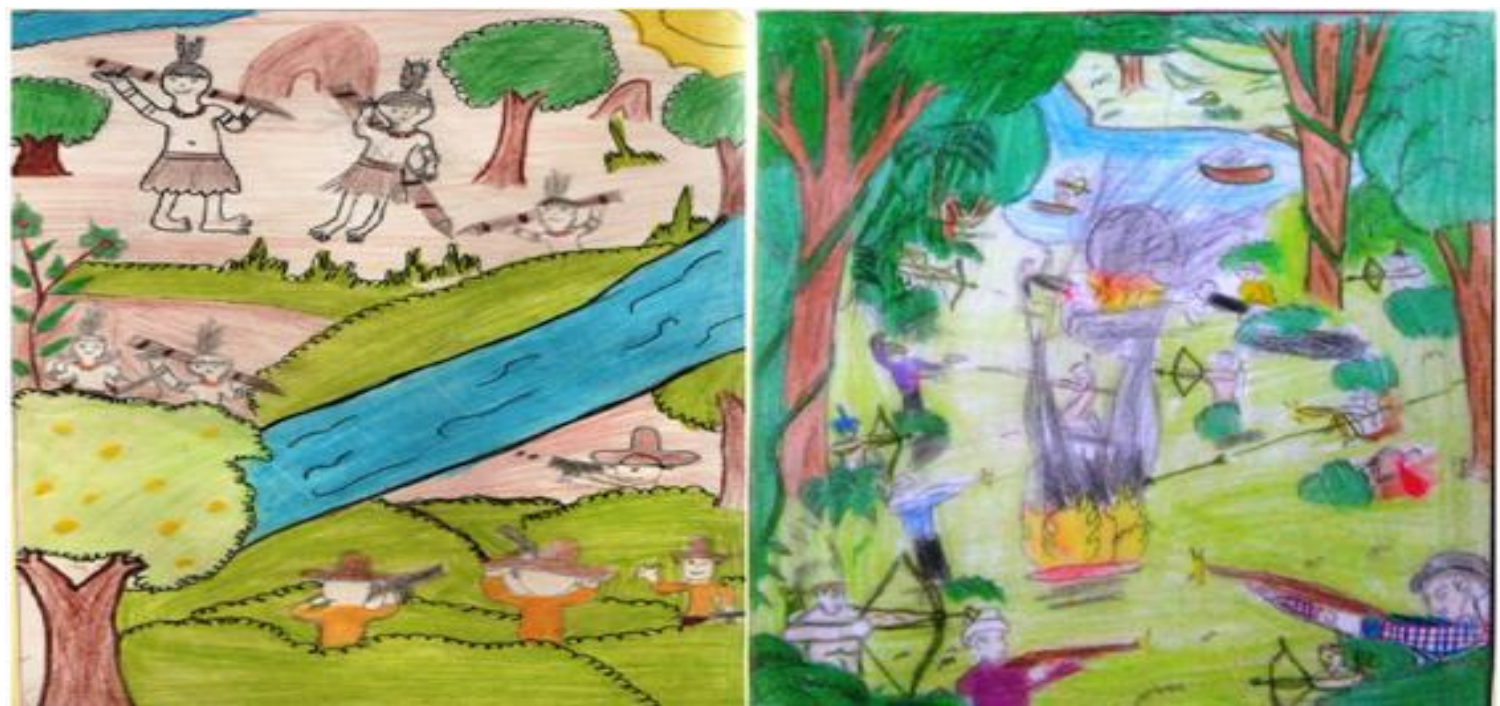

Figura 3: Tensão existente nos primeiros contatos dos Kaiowá com os Karaí

Autoria: Trabalhos elaborados pelos alunos da Escola Araporã, sob orientação da professora Alice. Fonte: Trabalho de campo, 2015.

Nos desenhos da Figura 3 identificamos a percepção dos alunos quanto às relações conflituosas que permearam os contatos entre os indígenas e os Karaí. Destaca-se nas ilustrações o sentido paradoxal atribuído ao fogo, utilizado pelos não indígenas como arma de domínio. Já para os indígenas, o fogo comparece como elemento simbólico de proteção, uma vez que a imagem apresenta uma distorção, possivelmente causada por uma proteção espiritual resultante do efeito da fumaça advinda do fogo doméstico, presente no desenho 2 da Figura 3.

Esta situação demonstra que a nova organização colonial/territorial do mundo, assim como a imposição de um único saber em detrimento de uma diversidade de saberes existentes não aconteceu sem resistência dos povos indígenas. Essas relações tiveram início com a chegada dos europeus, mas permanecem até os dias atuais e são percebidas quando os alunos representam a figura do colonizador nos primeiros contatos ressignificada através da imagem do proprietário de terras (presente no canto inferior do desenho da Figura 3) ilustrado por meio do chapéu e da camisa xadrez.

De maneira geral, os desenhos elaborados pelos alunos demonstram que por meio da prática desenvolvida, a professora Alice Rosane Benitespossibilita aos alunos a capacidade formar raciocínios espaciais. E "formar esses raciocínios é mais do que localizar, é entender as determinações e implicações da(s) localizações, e isso requer referências teórico-conceituais". (CAVALCANTI, 2002, p. 14)

A reflexão de Cavalcanti também dialoga com a prática desenvolvida por parte dos professores de Geografia atuantes nas escolas indígenas do município de Caarapó (MS) identificadas por Silva (2016) durante acompanhamento das aulas de Geografia na Escola Municipal Indígena Ñandejara Polo, em que constatou que os professores atuantes na referida escola, ao trabalharem os conteúdos propostos com base em um planejamento e livro didático - colonial/ocidental - buscam relacionar à visão 


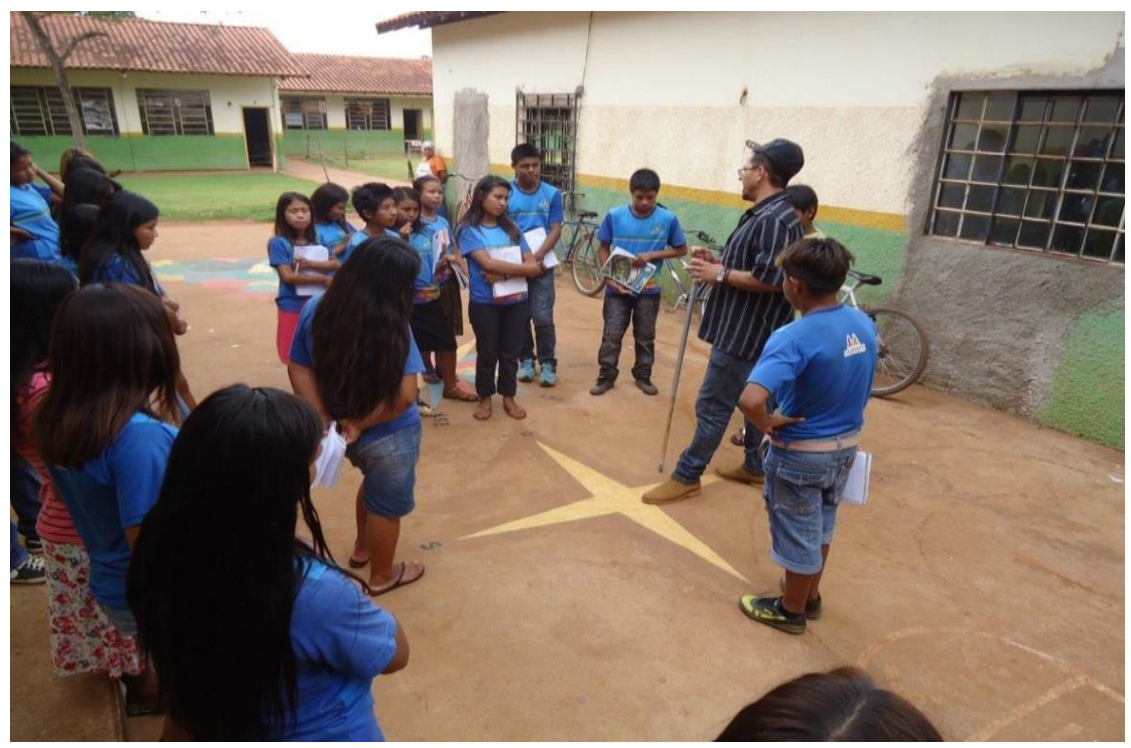

Figura 4: Atividades com os pontos cardeais

Fonte: Silva, D.M. (2015)

$\mathrm{Na}$ atividade ilustrada na Figura 4, o conteúdo proposto a ser trabalhado com os alunos do 6ำ ano foi pontos cardeais. Mas para além da orientação determinada pelos pontos cardeais, presente no livro didático, o professor buscou atribuir ao conteúdo significado para a vida dos alunos, uma vez que partindo da visão cósmica Guarani: "Os pontos cardeais enquanto forças que regem o mundo terreno indicam como os povos Guarani devem se orientar e localizar sua casa, sua roça e outros objetos de modo a manter uma sintonia com o lugar [...]". (LIMA, 2012, p. 85)

É importante destacar que a metodologia trabalhada na escola é subsidiada a partir de temas geradores, com base nos princípios de Paulo Freire. Assim, apesar do planejamento elaborado pelos professores apresentar maior ênfase nos conteúdos considerados "universais", a partir dos temas geradores busca-se ressignificar os conteúdos propondo o diálogo entre os conteúdos da Geografia institucionalizada ${ }^{3} \mathrm{com}$ as várias geografias existentes no espaço reserva.

No entender de Mota (2015), os Guarani e Kaiowá estão construindo suas estórias-trajetórias com uma relativa autonomia, e para compreendê-las é necessário o entendimento do espaço como coexistência de uma multiplicidade de estórias e práticas sociais em devir. As diferentes estóriastrajetórias dos Guarani e Kaiowá, também estão presentes nos desenhos elaborados pelos alunos da Escola MBo Eroy Guarani e Kaiowá, localizada na Reserva Indígena Amambai, no município de Amambai (MS).

Como podemos verificar na Figura 5, os alunos ilustram a necessidade de negociação colocada para os indígenas para continuarem sobrevivendo frente à nova realidade imposta. Neste sentido, acabam

\footnotetext{
3 Esta Geografia institucionalizada pode ser também compreendida conforme alguns autores como Oliveira Jr. (2009) como Geografia Maior do Estado, escrita com letra maiúscula (Geografia), produzida na macropolítica, nos gabinetes, expressa nos documentos, nos grandes mapas e projetos construídos com base nas estruturas da linguagem científica - referência de objetividade e verdade.
} 
por agenciar "outras" relações evidenciadas por meio da vestimenta (terno) utilizada como requisito necessário para ser aceito em determinadas áreas do mercado de trabalho da sociedade não indígena ou pela introdução de outras tecnologias. Porém, o aluno subverte a lógica a que foi submetido ao inserir elementos de expressivo significado para seu modo de ser (o cocar) ou por meio do texto escrito na tela do computador ("sou índio com muito orgulho"), ratificando a compreensão de que o fato de inserir na lógica do trabalho assalariado, ou utilizar de novas tecnologias, "não impediram que esses povos reinventassem incessantemente o seu caminhar". (MOTA, 2015, p. 121). Essa constatação está reafirmada nos desenhos da Figura 5, como podemos verificar a seguir.

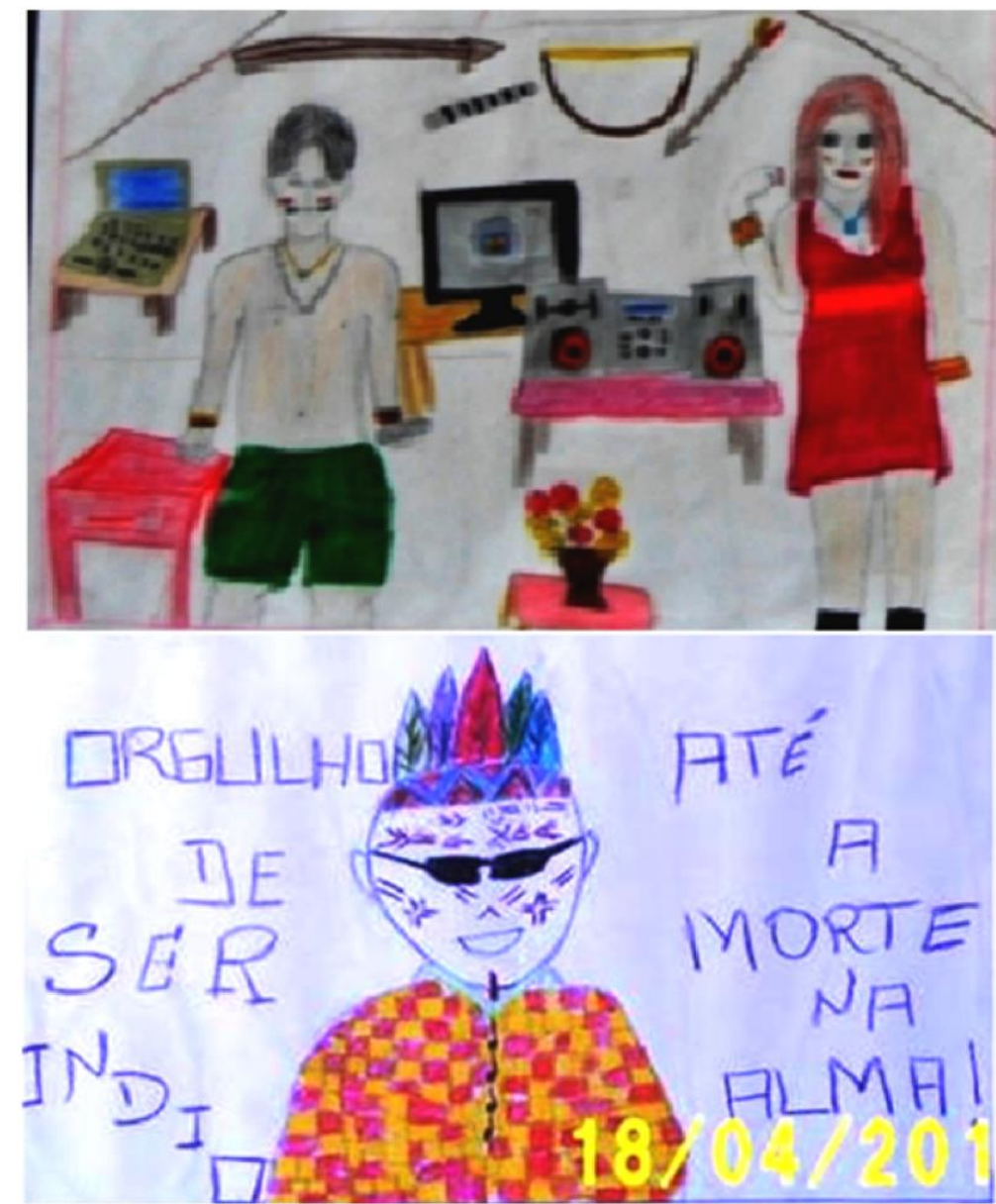

Figura 5: Cultura Guarani Kaiowá e o uso de novas tecnologias

Autoria: Trabalhos elaborados pelos alunos da Escola Estadual Indígena Guarani Mbo`Eroy Guarani Kaiowá

Fotos: Acervo da escola

Percebemos nas imagens contidas na Figura 5 a tentativa dos alunos em expressar que o fato de terem acesso a novas tecnologias não faz com que deixem de ser índios, uma vez que essas tecnologias são ressignificadas por eles através de seus símbolos. 0 computador, o aparelho de som, o televisor, são inseridos na imagem, ao mesmo tempo em que há uma preocupação na permanência dos elementos tradicionais de sua cultura (arco, flexa, bracelete). 0 tom forte das cores das roupas (o vermelho do vestido, o verde da bermuda) constrastam com as pinturas em seus rostos. E na imagem inferior do desenho, as cores presentes na camisa de chocam com o colorido do cocar: e na frase escrita, a mensagem que o desenho não pode expressar: "Orgulho de ser índio até a morte na alma!"

\section{Considerações Finais}


Considerando que trata-se de uma pesquisa em andamento, a análise realizada até o presente momento evidencia as particularidades e especificidades da luta por uma educação específica e diferenciada nas escolas indígenas dos três municípios pesquisados.

De maneira geral, identificamos que as práticas desenvolvidas, seja nos desenhos elaborados pelos alunos das Escolas Municipais Indígenas Araporã e Agustinho sob coordenação da professora Alice Rosane Benites, seja naqueles elaborados pelos alunos sob orientação dos professores de Geografia atuantes na Escola Ñandejara Polo a partir da metodologia dos temas geradores, ou pela metodologia de projetos desenvolvida nas escolas estaduais Guateka e Mbo'Eroy Guarani e Kaiowá, expressam as experiências de linguagem, de pensamento, de emoções, experimentadas nas aulas de Geografia.

Constatamos que a essência da Geografia (localização) possibilita diálogos com as diferentes geografias existentes nas reservas indígenas, uma vez que do ponto de vista do alvo de nossa pesquisa (a educação escolar indígena), esta particularidade geográfica traz consigo a raiz da questão política que permeia as construções dos diferentes saberes, hegemonizando alguns e subalternizando outros, dando sentido à necessidade de uma postura intercultural que permite a descolonização do saber geográfico estabelecido, em contraponto a discursos que foram sufocados porque não atendiam à lógica hegemônica instituída.

Acreditamos que saberes outros não podem ser inseridos nas escolas como mera reivindicação e que é preciso sistematizar esses saberes para dar sentido e significado à vida dos alunos.

\section{Referências Bibliográficas}

CASTELLAR. S. M. V. MORAES, J. V. SACRAMENTO. A. C. R. Jogos e resolução de problemas para o entendimento do espaço geográfico no ensino de geografia. In: CALLAI, Helena (Org.) Educação Geográfica: reflexão e prática. Ijuí/RS: Ed. Unijui, 2009, p. 249-276.

CAVALCANTI, Lana de Souza. Geografia e práticas de ensino. Goiânia: Alternativa, 2002.

KAERCHER, N. A., O gato comeu a geografia crítica? Alguns obstáculos a superar no ensinoaprendizagem de geografia. In. PONTUSCHKA, N. N., OLIVEIRA, A. U. de (org). In: Geografia em perspectiva: ensino e pesquisa, São Paulo, Contexto, 2002, p. 221-231.

SANTOS, Douglas. O que é Geografia? São Paulo, 2007, apostilado.

. O ensino da Geografia e o direito à escola e ao conhecimento. São Paulo, 2016. Disponível em: http://www.olharesgeograficos.com.br. Acesso em: 20/02/2017.

SILVA, Danielli Manfré da. O ensino de geografia na educação escolar indígena: reflexões com base na escola municipal indígena ñandejara poló em caarapó (MS). 2016. 122 p. Dissertação (Mestrado em Geografia) - FCH, UFGD, Dourados-MS.

SILVA, Solange Rodrigues da. A Geografia na educação escolar indígena: limites e Possibilidades para a construção da educação Intercultural. 2013. 143 p. Dissertação (Mestrado em Geografia) - FCH, UFGD, Dourados-MS.

SKLIAR, Carlos. Pedagogia (improvável) da diferença. E se o outro não estivesse aí? Rio de Janeiro: DP\&A, 2003. 224 p. 